\title{
autêntica
}

\author{
ARTIGOS
}

\section{PARCERIA UNIVERSIDADE-ESCOLA BÁSICA E A APRENDIZAGEM DA DOCÊNCIA: CONTRIBUIÇÕES DA RELAÇÃO ENTRE OS PROFESSORES SUPERVISORES DO PIBID E OS LICENCIANDOS BOLSISTAS}

Talita da Silva Campelo

Giseli Barreto da Cruz

\begin{abstract}
RESUMO: O presente artigo toma como referência dados coletados para fins de uma pesquisa sobre os diferenciais da parceria universidade - escola básica para a formação inicial de pedagogos docentes no contexto do Programa de Bolsa de Iniciação à Docência (PIBID) - proposto pela CAPES. Cuida de analisar as ações desenvolvidas nesse projeto, adotando como foco investigativo as intervenções e mediações das professoras supervisoras das escolas parceiras. Metodologicamente foi desenvolvido um estudo de caso. A partir de pressupostos teóricos construídos com base nos estudos de Cochran-Smith \& Lytle (1999) e Zeichner (2010), buscou-se discutir o trabalho desenvolvido no PIBID investigado. Os resultados apontam que ao promover a aproximação entre universidade e escola - viabilizada em um espaço de formação inicial onde se discute, se problematiza e se exercita o trabalho docente sob orientação e na companhia constante do professor da escola básica - o Programa PIBID potencializa a aprendizagem da docência dos licenciandos bolsistas investigados. Essa aprendizagem se expressa no favorecimento da compreensão da indissociabilidade entre teoria e prática.
\end{abstract}

PALAVRAS-CHAVE: Pedagogos docentes; PIBID, Parceria universidade-escola básica, Relação teoria \& prática

\section{PARTNERSHIP UNIVERSITY - PRIMARY SCHOOL AND THE TEACHER LEARNIN: CONTRIBUTIONS RELATED TO THE ROLE PLAYED BY THE PIBID SUPERVISORY TEACHERS AND UNDERGRADUATE STUDENTS}

\begin{abstract}
This article analyses data collected for a research on a project based on the partnership between university and primary school. This program endorses teachers' training opportunities by providing Scholarship Programs for Teaching contexts (PIBID) - proposed by CAPES. We have focused on the actions developed in this project, aiming at scrutinizing the investigative measures which take place during interventions and mediations between supervisory teachers and undergraduate students. Methodologically, it was established a case study. In order to sustain our positions, we have resorted to the theoretical assumptions built by the studies of Cochran-Smith \& Lytle (1999) and Zeichner (2010), sought to discuss the influences of PIBID. The results show that to promote closer ties between university and school - findings highlight the need to provide spaces and opportunities to discuss and problematize teachers' work and pedagogical choices. To sum up, PIBID program enhances good learning/professional opportunities for new teachers (undergraduate fellows). This learning encompasses the indivisibility of theory and practice.
\end{abstract}

KEYWORDS: Teachers; PIBID Partnership university - primary school, theory \& practice. 


\section{INTRODUÇÃO}

Corresponder às reais necessidades apresentadas pelo cotidiano escolar contemporâneo é um desafio que se coloca ao exercício profissional docente que, atualmente, precisa ultrapassar a prática de aplicar uma teoria aprendida ou de meramente reproduzir procedimentos e/ou metodologias utilizados em outros contextos. Para Tardif e Lessard (2005), o magistério não pode ser colocado como uma ocupação secundária. Ele constitui um setor nevrálgico nas sociedades contemporâneas e é uma das chaves para entender as suas transformações. A docência não é um trabalho simples e, portanto, a formação para esse exercício profissional é notoriamente complexa.

As pesquisas que se dedicam a essa temática têm suscitado muitas preocupações sobre os atuais moldes de formação docente. Ao tratar da formação inicial dos professores para a educação básica, muitos estudos têm constatado uma distância entre o processo de formação inicial dos professores e a realidade encontrada nas escolas, que diz respeito à lacuna entre a teoria estudada nas universidades e a prática desenvolvida no ambiente profissional, entre a formação e o trabalho (COCHRAN; M. S. LYTLE, 1999; ROLDÃO, 2007; ZEICHNER, 2010).

Diante desse quadro, a parceria universidade-escola básica tem grande potencial para superar a desconexão entre a academia e a realidade escolar. Para Lüdke e Boing (2012), é urgente que se construa uma parceria efetiva entre essas duas instituições formadoras do professor para que se atente para o trabalho docente e assim se possa aproximar a formação inicial das necessidades que o futuro professor irá enfrentar. Isso implica o reconhecimento de que existem determinados aspectos do exercício docente que podem ser melhor desenvolvidos a partir da problematização e da investigação sobre a docência com base no que ela é e de quem a faz: os professores.

É nesse contexto que surge o Programa Institucional de Bolsas de Iniciação à Docência (PIBID). Integrante do Plano Nacional de Formação de Professores (2009), o PIBID é um programa brasileiro de iniciação à docência que visa a participação de licenciandos em atividades de ensino-aprendizagem desenvolvidas na escola pública. O programa é desenvolvido por meio da concessão de bolsas de iniciação à docência para estudantes, bolsas de coordenação para professores coordenadores (instituições de ensino superior) e bolsas de supervisão para professores supervisores (escola básica). Seu lançamento ocorreu em dezembro de 2007, mediante o Edital MEC/CAPES/FNDE ${ }^{1}$. $^{\circ}$ 01/2007.0 programa permite que os licenciandos experimentem a docência através do planejamento e desenvolvimento coletivo -que une licenciandos, professores da escola básica (supervisores) e professores da universidade (coordenadores) - de atividades de aula, materiais didáticos e projetos interdisciplinares voltados para a escola pública.

Concentrando-nos no PIBID Pedagogia de uma universidade federal do Rio de Janeiro, nos interessa analisar as ações desenvolvidas nesse projeto, adotando como foco investigativo as intervenções e mediações dos professores supervisores das escolas parceiras. Quais as contribuições do papel desenvolvido pelas professoras supervisoras do PIBID Pedagogia para a formação inicial do pedagogo docente na perspectiva da parceria universidade-escola básica?

\section{ASPECTOS TEÓRICOS E METODOLÓGICOS}

Visando atender aos objetivos de investigar as contribuições da participação de professores da escola básica como coformadores de pedagogos docentes no contexto do PIBID Pedagogia, analisar o trabalho desenvolvido

1 Ministério da Educação (MEC); Coordenação de Aperfeiçoamento de Pessoal de Nível Superior (CAPES); Fundo Nacional de Desenvolvimento da Educação (FNDE). 


\section{autêntica}

pelos professores supervisores com os licenciandos participantes do programa e compreender como se constituem as intervenções desses professores supervisores no processo de formação docente dos licenciandos bolsistas, nos ficou claro o quanto se fazia necessário uma imersão profunda tanto nos processos em si quanto nos sujeitos que os mobilizavam.

Diante disso, metodologicamente, desenvolvemos um estudo de caso holístico com base nos pressupostos de André $(2005,2013)$ e Yin (2010), construindo evidências no contato direto com os sujeitos envolvidos no projeto: uma professora coordenadora (universidade), cinco professoras supervisoras (escolas parceiras) e catorze licenciandos bolsistas. O caso se forja na especificidade do PIBID Pedagogia da instituição investigada, cuja prática requer que os bolsistas façam etnografia da prática escolar, se inserindo na turma semanalmente como copartícipe dela, indo além da proposta de desenvolver atividade de ensino em tempo específico, o que requer um convívio prolongado de aprendizagem sobre a docência sob a intervenção da professora supervisora. ${ }^{2}$

Durante o período de imersão em campo, foram feitas observações, entrevistas e análise documental. As entrevistas se deram apenas com os professores supervisores, uma vez que a convivência direta com os licenciandos bolsistas permitiu captar suas impressões continuamente. Quanto aos documentos, foram analisados tanto documentos oficiais (como editais) quanto escritas e materiais produzidos pelos licenciandos e por professoras supervisoras durante o período em que estivemos em campo. A observação se deu em duas fases: a primeira fase foi desenvolvida nos encontros semanais do PIBID Pedagogia na universidade. A segunda fase ocorreu na sala de aula do professor supervisor de uma das escolas parceiras.

QUADRO 01: ORGANIZAÇÃO DOS DADOS COLETADOS

\begin{tabular}{|c|c|}
\hline INSTRUMENTOS DE COLETA DE DADOS & QUANTIDADETOTAL \\
\hline OBSERVAÇÃO & 21 \\
\hline ENTREVISTA & 10 \\
\hline $\begin{array}{l}\text { ANALISE DOCUMENTAL (atas dos encontros semanais na } \\
\text { universidade; roteiros de produção de material didático; portfólios; } \\
\text { produções acadêmicas (banners, slides para congressos, oficinas, } \\
\text { resumos publicados); relatos de experiência (em áudio e escritos); } \\
\text { editais MEC/CAPES/FNDE n. }{ }^{\circ} 01 / 2007, \text { n. }^{\circ} 02 / 2009, \text { n. }{ }^{\circ} 18 / 2010 \text {, } \\
\text { n. }{ }^{\circ} 01 / 2011, n .^{\circ} 11 / 2012 \text { e } n .^{\circ} 68 / 2013 \text {; relatório interno } 2014 \text { ) }\end{array}$ & 65 \\
\hline
\end{tabular}

Fonte: Dossiê da pesquisa

Para análise e interpretação dos dados, utilizamos uma estratégica analítica geral (YIN, 2010) voltada para o exame, a categorização, a tabulação, para tirar conclusões baseadas empiricamente. Para isso, foi usado um dos quatro eixos propostos por Yin (2010): o exame dos dados a partir das proposições teóricas. Foram usadas também técnicas específicas da análise dos estudos de caso propostas pelo autor, como a combinação de padrão, a construção da explanação e a síntese cruzada dos dados.

\footnotetext{
${ }^{2}$ No PIBID investigado, as atividades feitas pelos licenciandos bolsistas nas escolas parceiras não ocorrem no contraturno das aulas, como é comum em outros projetos. Elas se desenvolvem ao longo da aula do professor supervisor, que lhes cede tempo e espaço. Os pibidianos desse caso passam uma tarde por semana na sala de aula do professor supervisor e assistem ao seu trabalho (participando e interferindo nele). Em uma parte da aula assumem uma atividade planejada e desenvolvida nos encontros na universidade.
} 


\section{autêntica}

Para fundamentar nosso estudo, nos apoiamos em três autores: Zeichner (2010), Cochran-Smith e Lytle (1999). Nossas proposições teóricas decorrem do estudo sobre dois eixos: relação teoria-prática e parceria universidade-escola básica. Direcionamo-nos ao desenvolvimento de terceiros espaços como facilitadores da articulação entre as dimensões teóricas e práticas do conhecimento sobre a docência (ZEICHNER, 2010) e, de igual modo, às concepções de formação de professores que preveem a troca de saberes entre docentes experientes e em formação inicial (COCHRAN-SMITH e LYTLE, 1999).

Os terceiros espaços de formação docente, tal como proposto por Zeichner, estão focados "na criação de novas espécies de papeis para os formadores de professores e nos meios de aproximar conhecimento acadêmico e profissional" (2010, p.486). Nessas configurações, o trabalho desenvolvido no PIBID traz duas importantes ideias para se pensar a formação docente: a participação de professores da educação básica na formação inicial de outros professores e a antecipação/extensão do tempo que os licenciandos passam na escola - seu futuro campo de atuação.

No entanto, estar com professores experientes e passar mais tempo na escola não parece ser suficiente para melhorar a formação docente em uma perspectiva de superar a distância entre a formação e o trabalho (COCHRAN-SMITH e LYTLE, 1999; GATTI, 2008, 2010 e 2013; ROLDÃO, 2007; ZEICHNER, 2010). Nesse sentido, o diferencial de espaços híbridos - terceiros espaços - para a formação inicial de professores se materializa quando, para além de grupos de encontro, eles se configuram como "comunidades intelectuais, sociais e organizacionais que dão suporte à aprendizagem de professores, promovendo oportunidades para que pensem, falem, leiam e escrevam sobre seus trabalhos diários, de maneira intencional e planejada". (COCHRAN-SMITH e LYTLE, 2002).

A mobilização de professores da escola básica para coformarem licenciandos através de processos de problematizar, investigar, pensar e agir sobre o trabalho docente a partir dele próprio contraria o "modelo de fora para dentro, no qual o saber está primordialmente entre os acadêmicos e não entre os professores da Educação Básica" (ZEICHNER, 2010). Nesse sentido, espaços que equilibram conhecimento profissional e conhecimento acadêmico trazem novas possibilidades para se pensar o acesso dos futuros professores aos saberes que compõem o trabalho docente. Compreendemos que determinados aspectos da docência precisam ser desenvolvidos em contexto real de trabalho: na escola. Defendemos, portanto, que a formação inicial docente precisa ser desenvolvida com base em uma concepção que considere a indissociável relação entre teoria e prática. Acreditamos que modelos formativos que privilegiem a parceria universidade-escola básica são potentes para isso.

Quanto a isso, para Roldão (2007), as diversas especificações da docência não residem nessa lógica de alternância -pedagógico ou científico-, mas sim na sólida construção de um saber científico-profissional integrador de todos os saberes que se mobilizam para a prática da ação de ensinar enquanto fazer aprender alguma coisa a alguém. Isso incide diretamente em uma formação docente que articule as dimensões teóricas e práticas, permeando-as por momentos de análise, contextualização e, principalmente, investigação crítica sobre o fazer pedagógico.

Quanto a esses aspectos, identificamos diferenciais importantes no PIBID. Entre eles destacamos a concessão de bolsas não só aos licenciandos, mas também aos professores da universidade que os orientam e aos professores da escola básica que os supervisionam. Destacamos também dois pontos que para nós são muito caros: a oportunidade de pensar e fazer a docência com professores da escola básica em contexto real de trabalho e a imersão precoce (e em ciclo contínuo) dos licenciandos na escola. 


\section{autêntica}

O PIBID também inclui a possibilidade de contato imediato e contínuo com a escola, flexibilizando marcações temporais em relação à permanência no programa (os licenciandos bolsistas podem participar do programa pelo tempo que quiserem e puderem). Com relação à Pedagogia, foco deste trabalho, o PIBID favorece a chance de imersão aprofundada no trabalho docente, tendo o licenciando a possibilidade de acompanhar por mais de seis meses determinada etapa de ensino (educação infantil, anos iniciais do ensino fundamental, etc.), o que nem sempre é possível com o estágio curricular. Essas características distintas do programa certamente imprimem mudanças na formação dos pibidianos. ${ }^{3}$ Concentrando-nos no PIBID Pedagogia, é isso que nos interessa investigar.

Para fins do presente texto, foram selecionados alguns aspectos da pesquisa considerados relevantes, tendo em vista os objetivos definidos. Os resultados que aqui trazemos se referem à totalidade da análise dos dados colhidos ao longo de toda a imersão em campo. Este artigo focalizará a aprendizagem da docência que se forja na relação entre professores supervisores e licenciandos bolsistas, ${ }^{4}$ tendo em vista as estratégias mobilizadas pelas professoras supervisoras e as suas implicações para favorecer o entendimento da indissociabilidade entre teoria e prática no que se refere ao trabalho docente.

\section{APRENDIZAGEM DA DOCÊNCIA NA RELAÇÃO ENTRE PROFESSORAS SUPERVISORAS E PIBIDIANOS: A RELAÇÃO TEORIA E PRÁTICA}

A pesquisa que relatamos se desenvolveu durante um período de dois anos (2014 e 2015), e a imersão em campo se deu entre o primeiro semestre de 2014 e o segundo semestre de 2015. Delimitam-se em vinte os sujeitos desta pesquisa: um professor coordenador, cinco professoras supervisoras ${ }^{5}$ e catorze licenciandos bolsistas.

Todas as professoras supervisoras possuem formação docente anterior à graduação em Pedagogia (Magistério em nível médio) - primeira escolha de curso de todas, exceto de Sup 5, que graduou-se primeiramente em Serviço Social. Salvo uma professora supervisora, as demais fizeram graduação na rede pública e têm mais de 18 anos de docência. Apenas Sup 4 e Sup 5 não lecionaram na rede privada, ainda que a última possua experiência docente em espaços não escolares. Todas as professoras supervisoras observadas estavam em sua primeira experiência no PIBID.

Com relação aos pibidianos do grupo, apenas um é do sexo masculino. O projeto conta com um grupo bem heterogêneo com relação ao período de curso e à experiência na sala de aula. Dos catorze ${ }^{6}$ licenciandos bolsistas, cinco estão finalizando a graduação, enquanto seis ainda nem começaram os estágios supervisionados. Os três restantes já começaram suas práticas, mas suas primeiras experiências na escola como licenciandos foram no PIBID Pedagogia investigado.

3 Os licenciandos bolsistas do PIBID investigado se autodenominam assim e por ser esse termo bem aceito por todos os membros do grupo. Optamos, então, por usá-lo para designá-los.

4 Conforme o termo de consentimento assinado pelos sujeitos da pesquisa, a identidade de todos os envolvidos será preservada. Para fins de organização, foram utilizados codinomes: PIB seguido de número para os pibidianos bolsistas e SUP também seguido de número para os professores supervisores. Não utilizamos codinome para o professor coordenador porque ele não está no foco da nossa pesquisa.

5 Entrevistamos e consideramos na análise dos dados a primeira supervisora do programa investigado pelo tempo que ela permaneceu na função (um ano e meio), ainda que não a tenhamos observado em exercício.

6 Durante a imersão em campo, um dos pibidianos desligou-se do programa e logo foi substituído, não se alterando, assim, a quantidade de bolsistas (saiu Pib 13 e entrou Pib 14). 
A pesquisa mostrou que no PIBID Pedagogia investigado tem sido desenvolvido um modelo que prioriza a construção coletiva, a relação dialógica e a formação docente articulada à de pesquisa. ${ }^{7}$ Intenciona-se, assim, uma troca e uma construção de saberes pela organização de momentos em que os licenciandos compartilham com a professora coordenadora e com os professores supervisores as impressões construídas a partir das observações feitas durante o acompanhamento dos alunos das instituições parceiras, refletindo e aplicando, tanto nas reuniões na universidade quanto na própria turma onde atuam, ${ }^{8}$ os saberes que são construídos.

Conforme observamos, a proposta do projeto investigado estimula os bolsistas a planejarem e a realizarem atividades de ensino semanalmente. Estimula também a produção de registros tanto das observações, impressões e sentimentos quanto das ações planejadas e desenvolvidas, refletindo e aplicando os saberes que são construídos.

Muitos foram os relatos que demonstram que participar do PIBID investigado contribuiu para a escolha dos pibidianos pela docência. Pib 3 declara que "o projeto foi decisivo na minha escolha de permanecer na Pedagogia. Participando dele vi o quanto me identifico com a carreira docente" (portfólio Pib 3). Os relatos mostram o peso que os pibidianos atribuem ao programa e às ações nele desenvolvidas para sua formação docente.

Para os pibidianos, viver o trabalho docente, o problematizando, o investigando e atuando sobre ele, é de suma importância para conhecer aspectos da docência que se escondem na "experiência" de quem as vive. Oportunizar que licenciandos experimentem o ensino - tanto planejando, quanto aplicando e avaliando - em movimento contínuo e recursivo e, mais ainda, sob a segurança e a chancela do professor da escola básica e do professor da universidade, favorece o aprendizado da docência em uma perspectiva de conhecer o ofício docente e identificar em si mesmo a possibilidade de exercício da função: "eu descobri que posso ser professora" (comunicação oral Pib 1).

Quanto a essa aprendizagem da docência, os dados revelam também que os pibidianos perceberam como o trabalho docente é marcado por conexões teórico-práticas ao serem instigados por suas supervisoras a fazê-las e ao verem na prática como elas tomam forma. Os pibidianos desse caso relatam, com muita satisfação, o quanto participar do PIBID Pedagogia tem sido contributivo para ajudá-los na relação teoria-prática. Tanto em conversas informais quanto em portfólios, relatos de experiência e autoavaliações, ideias relacionadas à relação teoria-prática estavam, em maior ou menor proporção, sempre presentes.

Pib 3 relata que, "ao decidir participar do projeto, tinha em mente que seria a oportunidade de aprender coisas que acreditava não ter a chance de aprender na sala de aula da faculdade". Sobre essa intenção, viu-se realizada, porque "após a minha entrada, vi que realmente seria um aprendizado diferente, pois o PIBID, para mim, uniu a teoria e a prática com um grande enfoque na nossa formação como futuros docentes" (autoavaliação Pib 3). Sobre essa oportunidade de se pensar e vivenciar a docência de um modo diferente do que comumente é feito na universidade, Pib 1 conta que

na faculdade a gente aprende o que as cartilhas passaram, o tradicional já passou [...]; tem que letrar, que a criança vai se alfabetizara partir de história, mas a gente não vê como fazer isso. Eu pensava, principalmente nas aulas de Alfabetização e Letramento, "tudo bem, a gente tem que

\footnotetext{
7 O PIBID investigado se pauta pela iniciação à docência em uma perspectiva de experienciá-la de modo planejado e contextualizado. O que ocorre é que esse planejamento e essa contextualização se dão por meio de análise reflexiva e problematizadora sobre o trabalho docente, o que se remete à necessidade de uma formação paralela em pesquisa.
}

8 Pibidianos, supervisoras e coordenadora se reúnem semanalmente na universidade. Os pibidianos são divididos em grupos menores para serem alocados nas escolas parceiras (onde também vão semanalmente), ficando sob acompanhamento direto do professor supervisor da escola em questão. 


\section{autêntica}

fazer isso, mas como?". Eu não me sentia preparada para chegar na turma e saber o que fazer [...]. E no PIBID foi a primeira vez que eu consegui ver como o professor alfabetiza uma criança dentro dessa perspectiva e foi muito... genial! (comunicação oral Pib 1).

Sobre isso, Pib 1 também relata como o fato de não apenas observar, mas também poder dialogar com um professor da escola básica sobre o que ele faz em sala de aula é contributivo para a aprendizagem da docência. Pib 1 nos conta como foi perceber o papel da leitura funcional na alfabetização:

[...] e foi aí, que nesse dia pelo menos, eu percebi que o livro, a história, é como uma chave pra aula. Sup 3 trabalha todos os outros temas e eles emergem da história, daquela leitura. As crianças vão falando, vão discutindo, vão pensando [...], e eu achei isso muito diferente porque eu nunca tinha vivenciado isso, essa autonomia, nem na minha formação escolar (comunicação oral Pib 1).

Pib 1 faz questão de ressaltar o papel de sua professora supervisora nesse processo. Para Pib 1,"isso foi uma coisa que eu aprendi com Sup3, vendo ela, gravando ela, conversando com ela [...], algumas coisas eu percebi, alguns elementos diferentes" (comunicação oral Pib 1). A seguir, outros relatos que seguem nessa direção:

A gente se inspira muito no que a supervisora faz, na prática dela, muitas coisas que eu vi, por exemplo, como é que você vai ensinar uma criança a ler, eu não estava preparada pra fazer isso [...] e ela mostrou como fazer [...]. Pra mim está ajudando muito a construir essas "coisas de escola" (comunicação oral Pib 3).

Sup2 me inspira muito na minha construção profissional porque quando eu vejo a forma como ela trabalha [...], é uma forma que eu pretendo levar para minha sala de aula (comunicação oral Pib 13).

Foi uma forma de poder ver na prática um jeito de alfabetizar diferente do que a gente costuma ver, baseado no que a gente via antigamente [...]. Sup3 busca muito ensinar através da leitura. Poder ver isso é uma forma de aprendizagem para minha futura prática e reforça muito a questão da valorização do que os alunos conhecem, o que eles trazem na bagagem e também nas novas significações que eles fazem já nas aprendizagens (comunicação oral Pib 2).

Sobre essa questão, ao avaliar o trabalho que desenvolveu quando supervisionava o PIBID investigado, Sup 1 declarou em entrevista que tinha a intenção de favorecer a relação entre teoria e prática. Inclusive, quando questionada sobre quais influências acreditava ter tido sobre seu grupo de pibidianos, afirmou que sua principal contribuição foi "fazer com que percebessem que na escola não é tudo só prático".

Eu consegui que eles compreendessem algumas coisas metodológicas. O que na faculdade de educação eles viam na metodologia especialmente voltada para a área da alfabetização, eu acho que eles conseguiram ver a prática aqui, sem deixar que cada um colocasse um pouco do seu saber, da sua forma de como acha que também deve ser a educação, como deve ser a prática docente (entrevista Sup 1).

Nas visitas de campo, observamos o quanto estimular relações teórico-práticas era uma estratégia recorrente. Em pelo menos quatro ocasiões diferentes, vimos Sup 5, por exemplo, perguntando diretamente aos pibidianos que relações eles faziam entre o trabalho dela e o que estudavam na universidade, entre o que eles estavam desenvolvendo e o que aprendiam nas aulas do curso na faculdade. 


\section{autêntica}

Na primeira vez, pediu que os pibidianos relacionassem o que estavam vendo de seu trabalho com o que estavam estudando no curso. Eles não conseguiram. Na semana seguinte, instigou os pibidianos a relacionarem a atividade que iriam desenvolver com o que estavam estudando na universidade. Os pibidianos não fizeram conexão de imediato; Sup 5 então apresentou as próprias relações teórico-práticas sobre a proposta de atividade. No encontro posterior, a conversa se repetiu: na avaliação da atividade feita pelos pibidianos, Sup 5 pediu que eles tentassem mais uma vez relacionar o que fizeram (no planejamento e na execução) ao que estavam aprendendo na faculdade. Dessa vez, se saíram melhor, conforme Sup 5 nos confidenciou depois: "ao menos tentaram". O processo se repetiu do mesmo modo na semana que se seguiu. Pib 3 fez relações, mas de forma negativa: sua atuação não foi boa diante das proposições teóricas para alfabetização. Sup 5 a tranquilizou e explicou teoricamente como cada ponto da atividade da pibidiana tinha sido positivo, evidenciando questões que ela não havia percebido.

Em entrevista, Sup 5 afirmou que "ficava tentando costurar a prática com a teoria que imagino que eles podem ter visto lá na universidade" por acreditar que "existem as coisas muito específicas de quem está dentro da universidade e de quem está dentro da escola básica. Essas coisas, elas podem se juntar em termos de formação". Sobre seu esforço para fazer com que os pibidianos percebessem o quanto/como seu trabalho estava relacionado aos aspectos teóricos, afirmou em entrevista que:

[...] eu ainda não consigo muito não, porque eu vejo que é muito difícil, mesmo para o aluno que tá aqui, fazer a relação entre o que tá acontecendo lá e o que tá sendo falado aqui. E também, eu como falo muito, eu fico querendo que o aluno fale, mas eu não quero tornar esse momento constrangedor, de ficar buscando (entrevista Sup 5).

A preocupação de Sup 5 reflete suas concepções de que os professores "mais competentes" têm profundo conhecimento do conteúdo de suas áreas e das estratégias mais eficazes de ensino para criar oportunidades de aprendizagem para estudantes. Suas ações demonstram a importância que atribuía ao domínio pelos pibidianos dos aspectos teóricos que baseiam as práticas. A dificuldade que eles tinham para ver as conexões teórico-práticas do trabalho de Sup 5 revelam um problema perene em programas tradicionais de formação de professores: "a falta de conexão entre os cursos de formação de professores e o campo da prática" (ZEICHNER, 2010, p. 483).

O autor aponta que, embora a maior parte dos programas universitários de formação de professores inclua múltiplos campos de experiência em toda a sua extensão, a desconexão entre o que é ensinado aos estudantes e suas oportunidades de aprendizagem para levar tais práticas em suas respectivas escolas não raramente é muito grande, inclusive nas escolas parceiras e nas de desenvolvimento profissional (ZEICHNER, 2010).

Sobre isso, Cochran-Smith e Lytle (1999) apontam que essa distância indicada por Zeichner se relaciona às premissas: (a) de que seja possível delinear dois tipos de conhecimento para o ensino, (b) de que essa distinção responde pelo universo de tipos de conhecimento para compreender o ensino e (c) de que o conceito de conhecimento prático captura adequadamente o trabalho de professores e a atividade de ensino. As autoras denunciam que essas implicações servem para retificar as divisões que colocam os professores em "seu devido lugar" - a separação entre praticantes e pesquisadores, fazedores e pensadores, atores e analistas, e ações e ideias (COCHRAN-SMITH e LYTLE, 1999).

As ações de Sup 5 para incentivar os pibidianos a fazerem relações teóricas com o que estavam observando/vivendo na prática mostram seu esforço para construir conhecimentos sobre a docência com eles, num 


\section{autêntica}

movimento que vai além de permitir que sua própria prática seja investigada e que contempla mostrá-los o porquê ensina dessa ou de outra maneira. Engajada nisso, nas primeiras semanas de setembro Sup 5 deu um minicurso durante uma parte dos encontros do PIBID que acontecem na universidade. Nesse minicurso, observamos Sup 5 apresentar as bases teórico-metodológicas da alfabetização a partir de exemplos do seu próprio trabalho.

Ao utilizar as próprias atividades e exemplos de situações que os pibidianos acompanharam em sua sala de aula, Sup 5 permitiu a eles fazer conexões teórico-práticas a partir da docência em si, o que, para Lessard, "num campo tradicionalmente dominado por teorias pedagógicas normativas, este enfoque no trabalho é uma importante etapa do desenvolvimento das ciências da educação" (LESSARD, 2009, p. 126).

Ao observamos momentos como o desse minicurso, percebemos no PIBID o desenvolvimento de um terceiro espaço (ZEICHNER, 2010) de formação inicial docente, que interliga conhecimentos acadêmicos e conhecimentos profissionais através da mobilização de professores da escola básica - professores supervisores - como coformadores de outros docentes. As contribuições das supervisoras se materializam quando elas compartilham nesses espaços seus saberes e fazeres sobre a docência em movimentos de desprivatização tanto das próprias práticas quanto das que os pibidianos constroem no contexto do programa.

A desprivatização da prática (COCHRAN-SMITH, 2012) abre o ensino e os saberes e fazeres que o permeiam ao escrutínio de outros. Esse processo permite o desenvolvimento de conhecimentos sobre a docência quando acompanhado de investigação e problematização dessas práticas em um sistema de colaboração com outros que também estejam engajados em tornar seu trabalho público e aberto a críticas. As ações que observamos no PIBID investigado permitem que os pibidianos experimentem a docência através do planejamento e do desenvolvimento coletivo -que une licenciandos, professores da escola básica (supervisores) e professores da universidade (coordenadores) - de atividades de aula, materiais didáticos e projetos interdisciplinares, que em todas as fases são abertos ao escrutínio do grupo.

Percebemos que nesse processo contínuo de planejar-executar-avaliar, tanto os pibidianos quanto as supervisoras refletem e problematizam sobre o trabalho docente ao compartilharem "seu" ensino com os outros, tornando público e coletivo processos que normalmente se mantêm ocultos atrás da porta da sala de aula. Desse modo, favorece a conexão entre o conteúdo a ser ensinado e as estratégias que melhor se adéquam ao objetivo estabelecido, passando pelo planejamento, pela execução e pela avaliação.

Para Pib 14, "o PIBID tem auxiliado nessa ponte entre o significado do conteúdo e a construção realizada pelos alunos" (relato de experiência Pib 14). Sobre isso, Pib 2 relata que "o pouco tempo como bolsista do PIBID já me acrescentou grandes ensinamentos, desde mais compreensão do universo da alfabetização até o aprimoramento no modo como me porto perante os alunos" (portfólio Pib 2). Pib 2 acrescenta ainda que tem aprendido muito "sobre a importância da busca constante de aperfeiçoamento por parte do professor para que sua prática esteja sempre se atualizando". Comparando como se portava na escola no começo e como estava meses depois, Pib 1 relata que

[...] se o aluno chegar pra mim e perguntar "está certo ou errado?", ao invés de dar a resposta, eu vou responder "vê lá, pensa como é que se escreve" ou pegar uma palavra de referência, que tenha a mesma sílaba no começo. Uma criança queria escrever "brasa", e eu disse "como se escreve Brasil? Pensa no Brasil" (comunicação oral Pib 1). 


\section{autêntica}

Quando pibidianos relacionam teoria e prática pela via do ensino através do acesso aos processos que acompanham professores experientes no planejamento e no desenvolvimento de atividades e através de exercícios de prática sob a supervisão desses mesmos professores, têm sua aprendizagem sobre a docência potencializada. Isso envolve diretamente o desenvolvimento de uma dimensão um tanto quanto esquecida na formação docente: o como ensinar. O lugar desse "como ensinar" se relaciona aos saberes e fazeres da docência pensados a partir da própria prática docente em si, conectando os conhecimentos acadêmicos e os conhecimentos profissionais de uma maneira que supere a desconexão entre escola e universidade.

Isso não implica necessariamente uma supervalorização da prática em detrimento da teoria, seja dos conhecimentos científicos pedagógicos ou de conteúdo, mas sim uma interseção entre eles baseada no ensino. Isso incide em uma formação docente que favoreça o desenvolvimento do conhecimento pedagógico, em um conjunto de formas alternativas de representação que encontram origem tanto na pesquisa como nos saberes oriundos da prática docente. Assim, esse conhecimento base para a docência vai, além do conhecimento da disciplina por si mesma, para uma dimensão do conhecimento da disciplina para o ensino.

Para Shulman (2005), a chave para distinguir o conhecimento pedagógico repousa na interseção entre conteúdos diversos e da pedagogia, na capacidade que um professor tem de transformar o conhecimento do conteúdo que ele possui em formas que sejam pedagogicamente eficazes e possíveis de adaptação às variações de habilidade e contexto apresentadas pelos alunos. Pensando no ensino enquanto mediação e movimento de dupla transitividade, como característica distintiva da docência e, portanto, potente norteador das práticas formativas de professores (ROLDÃO 2006, 2007), tanto o conhecimento pedagógico quanto o conhecimento didático do conteúdo são base para a docência que precisam de muito investimento na formação inicial.

No entanto, a identificação de conhecimentos diferentes que compõem a docência não pode significar que se tratam de "coisas separadas" que não se comunicam. Isso precisa ir além da ideia da prática e da teoria isoladas, do trabalho e da formação distanciados, da escola e da universidade desconexas. Para Roldão (2007, p. 37), "as diversas especificações, indispensáveis, não residem nesta lógica de alternância - pedagógico ou científico - mas sim na sólida construção de um saber científico-profissional integrador de todos os saberes que se mobilizam para a prática da ação de ensinar enquanto fazer aprender alguma coisa a alguém". Roldão ressalta ainda que isso não nega a existência, dentro desse saber profissional nuclear, de modalidades e especialidades. Defende, assim, que as especialidades decorrem desse saber "científico-profissional" global e desenvolvem-se dentro dele, e não o contrário (ROLDÃO, 2007, p.38). Entende-se, desse modo, que

[...] formar um profissional de ensino de qualidade significa torná-lo detentor de um saber muitíssimo rigoroso e que seja ativo, um saber em uso, um saber que se caracteriza por ser mobilizável e não um saber inerte. Significa ainda que esse saber profissional, com cujos instrumentos a formação desejavelmente apetrecharia os formandos, Ihes deverá permitir exercer bem a sua função em termos profissionais - e a sua função é ensinar, fazer com que os seus alunos aprendam aquilo que, por isso mesmo, eles também têm que saber muito bem, sabendo fazê-lo com autonomia de decisão e capacidade de análise, decisão e melhoria (ROLDÃO, 2007, p.39).

Quando isso ocorre, vemos aproximação com as propostas de Gatti para se repensar a concepção vigente sobre "prática" e "teoria". Segundo Gatti,

[...] prática educacional é prática social com significado e não pode ser tomada como simples receita, ou confundida com tecnicismos modeladores. Prática pedagógica, por ser pedagógica, é 


\section{autêntica}

ação política, de cidadania, comportando formas de ação guiadas por seus fundamentos, sejam filosóficos, sejam científicos. Implica fazer pensando e pensar fazendo, implica saber fazer e porque fazer, ou seja, implica uma praxiologia (GATTI, 2013, p. 55).

Para Cruz (2012), por esse caminho, a prática social constitui-se no principal mote do trabalho pedagógico, do qual emergirão, prática e teoricamente, as questões a serem problematizadas, os instrumentos para seu estudo e elucidação e as ideias para aplicação à própria vida dos sujeitos envolvidos nesse processo, favorecendo, assim, a unidade teoria-prática.

Quanto a isso, os dados deixam ver que a experiência no PIBID é potencializada com a atuação de professores híbridos (ZEICHNER, 2010): quando as professoras supervisoras se tornam formadoras atuando em um espaço que não é primariamente seu - a formação docente - e em uma função que não é primariamente sua - formar professores -, se fazem melhor aproximações entre universidade e escola pela via do trabalho docente, da experiência de quem vive o ensino na escola. Com isso, para as supervisoras, a participação no programa representa a oportunidade de retorno ao espaço da universidade em outro papel, na condição de formadoras, o que favorece um novo olhar sobre a própria prática e sobre a escola. É nessa interface que se mostram as maiores diferenças que o PIBID traz para a formação de professores.

Percebemos o esforço das supervisoras em se mostrarem para os pibidianos não como meras executoras de práticas, mas como "profissionais detentores de ideias e práticas educativas fecundas, ou seja, preparados para a ação docente com consciência, conhecimentos e instrumentos" (GATTI, 2013, p.54). Está claro que para pibidianos e para professoras supervisoras a relação teoria e prática foi favorecida nos processos formativos que envolvem o PIBID Pedagogia. Tal como observamos, a relação teoria e prática que se construiu nesse processo contribuirá para que os licenciandos compreendam que "práticas educacionais são processos da maior importância, têm seus fundamentos teóricos e associam-se a uma filosofia educacional. Práticas geram teorizações e teorizações geram práticas, em movimento recursivo" (GATTI, 2013, p.54). 


\section{autêntica}

\section{CONCLUSÕES}

Ao analisar o trabalho desenvolvido pelas professoras supervisoras com os licenciandos participantes do PIBID Pedagogia investigado, percebemos como professoras da escola básica e licenciandos podem compartilhar e desenvolver saberes.

Constatamos que, muito além de permitir que sua prática seja investigada - o que vemos, por exemplo, no estágio curricular -, no PIBID investigado as professoras da escola-básica expõem constantemente a escrutínio, julgamento e análise o que ensinam, porque ensinam e como ensinam. Percebemos que quando licenciandos podem dialogar sobre o trabalho docente e experimentá-lo com o apoio de professores experientes a aprendizagem sobre o oficio de ensinar é potencializada.

A pesquisa nos mostrou que no PIBID Pedagogia investigado o relacionamento de ensino/aprendizagem da docência que se dá entre os pibidianos e as supervisoras não ocorre de modo neutro e natural. Pelo contrário, é notoriamente marcado pelas distintas visões sobre formação inicial, sobre o que "quer se dar" e o "quer receber." No entanto, ficou claro que, a despeito dos antagonismos que ora se acentuavam e das diferentes formas de se relacionar que os sujeitos construíam, o compromisso com o desenvolvimento da docência não se perdia. O foco é o aprendizado da docência, a iniciação à docência, e isso não é desconsiderado. $\mathrm{A}$ seriedade com que se assume esse lugar exige das supervisoras diversas mediações e intervenções, ora mais assertivas, ora mais propositivas - sempre em um ambiente de troca e diálogo.

Soma-se a isso a necessidade de as professoras supervisoras encontrarem o equilíbrio entre a responsabilidade com a formação de seus alunos e a formação dos pibidianos com os quais precisam dividir atenção. É nesse papel de professor híbrido (ZEICHNER, 2010) e nos dilemas que ele suscita que percebemos as sutilezas de ser um professor supervisor.

Os depoimentos dos pibidianos ilustram como presenciar práticas de professores experientes e poder pensar sobre elas com esses mesmos professores é importante para favorecer a relação teoria e prática. Os dados, no entanto, não nos mostram nitidamente a "teoria" da relação teoria e prática. Observamos que os pibidianos, apesar de se verem como os que têm os conhecimentos acadêmicos, não os têm tanto assim, seja por estarem nos primeiros períodos do curso ou por não terem acesso em seus percursos formativos aos conhecimentos acadêmicos que embasam e fundamentam o como ensinar. Percebemos que as conexões teórico-práticas são feitas majoritariamente pelo professor supervisor.

Ao evidenciá-las para os pibidianos, eles percebem a conexão entre academia e escola, entre a formação e o trabalho. Sendo assim, os pibidianos parecem ficar "reféns" do entendimento que o supervisor tem dessa relação. Quanto a isso, as observações nos mostraram que os pibidianos ainda não têm aporte nem teórico nem prático para se posicionarem com/contra as conexões entre os conhecimentos acadêmicos e profissionais que as supervisoras fazem. Percebemos que esse aporte está sendo construído (ampliado e consolidado) pelas ações do PIBID investigado, principalmente pelo movimento de problematizar e investigar o trabalho docente.

Infelizmente, a continuidade do PIBID, que nacionalmente ofertou mais de 72.000 bolsas no último edital (2013), está ameaçada devido a recorrentes cortes de verba que culminaram no risco do não oferecimento de novas bolsas para os próximos anos. Ainda que o discurso oficial sobre a questão seja de afirmar a 


\section{autêntica}

estabilidade do programa, aumentam a cada dia as preocupações de coordenadores, supervisores e licenciandos. Somam-se a isso as recentes tentativas de mudanças na estrutura do programa (2016), o que gerou grande mobilização tanto das universidades quanto das escolas-parceiras. Nos preocupa que essas mudanças afetem diretamente o relacionamento ente o professor supervisor e o pibidiano, uma vez que se referem ao aumento de licenciandos por supervisor e priorização de atividades desenvolvidas fora do contexto da sala de aula. Se essas propostas vigorarem, o que será feito do PIBID? Aqui se acentua a necessidade de mais estudos e pesquisas sobre o assunto, evidenciando os impactos do programa e traçando possibilidades de interlocução entre ele e a formação inicial docente como um todo. 


\section{autêntica}

\section{REFERÊNCIAS}

ANDRÉ, M. E. D. A. Estudo de caso em pesquisa e avaliação educacional. Brasília: Liber livro, 2005.

O que é um estudo de caso qualitativo em educação? Educação e Contemporaneidade, Salvador, v. 22, n. 40, p. 95-103, jul./dez, 2013.

COCHRAN-SMITH, M. A tale of two teachers: Learning of teach over time. 2012. In: Kappa Delta pi Record, july/sept, 2012, p. 108-122.

Lytle, S. L. Relationships of knowledge and practice: Teacher learning in communities. In: Review of research in education, ed. A. Iran Nejad and P. D. Pearson, 24(1): 249-305. Washington, DC: American Educational Research Association,

CRUZ, G. B. da. Práticas de formação em Pedagogia: dilemas e perspectivas. XVI ENDIPE - Encontro Nacional de Didática e Práticas de Ensino (Congresso). UNICAMP - Campinas, 2012.

GATTI, B.A. et al. Formação de professores para o ensino fundamental: instituições formadoras e seus currículos. Relatório de pesquisa. São Paulo: Fundação Carlos Chagas; Fundação Vitor Civita, 2008. 2 v.

A Formação de professores no Brasil: Características e problemas. Educação e Sociedade. Campinas, v. 31, n. 113, p. 1355-1379, out./dez. 2010.

Educação, escola e formação de professores: políticas e impasses. Educar em Revista, Curitiba, n. 50, p. 51-67, out./dez. 2013.

LESSARD, C. O Trabalho docente, a análise da actividade e o papel dos sujeitos. Sísifo: Revista de Ciências da Educação, Lisboa, n. 9, p. 119-127, 2009.

LÜDKE, M.; BOING, L. A. Do trabalho à Formação de Professores. Cadernos de Pesquisa, v. 42, n.146, p. 428-451, maio/ago. 2012.

PIBID - UFRJ - O PIBID. Disponível em: < www.pibid.pr1.ufrj.br >. Acesso em: 27 jan. 2015.

ROLDÃO, M. do C. Formar para a excelência profissional: pressupostos e rupturas nos níveis iniciais da docência. Educação \& Linguagem, n. 15, p. 18-42, jan./jun. 2007.

A formação de professores como objecto de pesquisa: contributos para a construção do campo de estudo a partir de pesquisas portuguesas. Revista Eletrônica de Educação, Universidade Federal de São Carlos, 2006. Disponível em: <www.portaldosprofessores.ufscar.br>.

SHULMAN, L. S. Conocimiento y enseñanza: fundamentos de la nueva reforma. Profesorado: Revista de curriculum y formación del profesorado, v. 9, n. 2, p. 1, 2005.

TARDIF, M.; LESSARD, C. O Trabalho docente: elementos para uma teoria da docência como profissão de interações humanas. Petrópolis: Vozes, 2005.

YIN, R. K. Estudo de caso: planejamento e métodos. Porto Alegre: Bookman, 2010.

ZEICHNER, K. Repensando as conexões entre a formação na universidade e as experiências de campo na formação de professores em faculdades e universidades. Educação, Santa Maria, v. 35, n. 3, p. 479-504, set./dez. 2010. 